\title{
Why and how Sen's capability approach should deal with corporate governance
}

Magali Fia, Lorenzo Sacconi and Massimiliano Vatiero

Published Online: 26 Jul 2021|https://doi.org/10.5465/AMBPP.2021.11403abstract

\section{Abstract}

The hierarchical nature of the firm affects stakeholders' well-being. This is our main motivation in analysing the firm through the perspective of Sen's capability approach-a social justice theory for the evaluation of any institution, organization or policy aimed at providing well-beings. In order to work out the inherent relation between the capability approach and the economic analysis of the law, we show the strict link between capabilities and entitlements, which we call capabilities-as-entitlements, and investigate if and how corporate governance, i.e., the configuration of entitlements in a firm, enhances or diminishes capabilities of stakeholders. We underline the role that the public use of reason and a sufficientarian criterion play in mitigating conflicts among stakeholders, permitting the reach of a balance amongst all of them and the identification of the capabilities that allow stakeholders to exercise democratic citizenship in corporation. We build several indexes that are able to measure and compare capabilities developed within and between corporate governance regimes. 

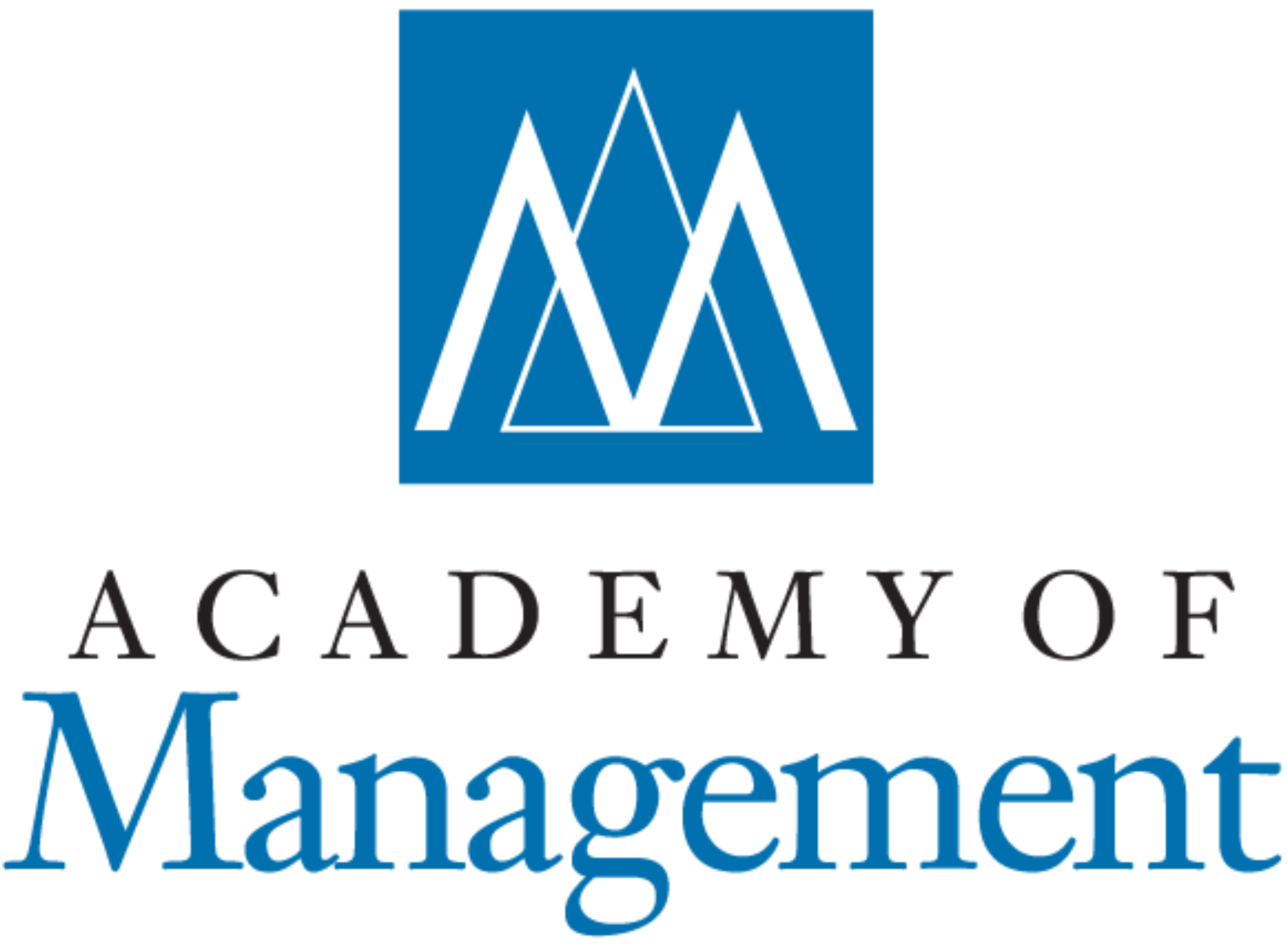

Academy of Management

555 Pleasantville Road, Suite N200

Briarcliff Manor, NY 10510-8020, USA

Phone: +1 (914) 326-1800

Fax: +1 (914) 326-1900

Privacy Policy Logo Use

(c) 2021 Academy of Management

Powered by Atypon ${ }^{\circledR}$ Literatum 